\title{
A novel framework combining BCI and IOT for the detection of activity of the brain
}

\author{
B Karthiga ${ }^{1 *}$ and M Rekha ${ }^{2}$ \\ Department of Electronics and Communication Engineering, Dhanalakshmi Srinivasan Engineering \\ College, Perambalur-621212, India
}

Received: 06 September, 2021

Accepted: 17 September, 2021

Published: 18 September, 2021

*Corresponding author: B Karthiga, Department of Electronics and Communication Engineering, Dhanalakshmi Srinivasan Engineering College, Perambalur-621212, India, E-mail: karthiga.jaya@yahoo.com, karthiga.jaya15@gmail.com

ORCID: https://orcid.org/0000-0001-8009-960X

Keywords: BCl; IoT; EEG sensor; Cloud; Machine learning; Arduino

Copyright: (c) 2021 Karthiga B, et al. This is an openaccess article distributed under the terms of the Creative Commons Attribution License, which permits unrestricted use, distribution, and reproduction in any medium, provided the original author and source are credited.

https://www.peertechzpublications.com

\section{Check for updates}

\section{Abstract}

Virtual brain research is accelerating thedevelopment of inexpensive real-time Brain Computer Interface (BCl). Hardware improvements that increase the capability of Virtual brain analyse and Brain Computer wearable sensors have made possible several new software frameworks for developers to use and create applications combining $\mathrm{BCl}$ and IoT. In this paper, we complete a survey on $\mathrm{BCl}$ in loT from various perspectives; including Electroencephalogram (EEG) based $\mathrm{BCl}$ models, machine learning, and current active platforms. Based on our investigations, the main findings of this survey highlights three major development trends of $\mathrm{BCl}$, which are $\mathrm{EEG}$, loT, and cloud computing. Using this it is completely useful for finding the true state of whether the brain is alive or dead. If it is alive, then the activity of the brain is monitored and stored. Through this anyone can come to conclusion that whether the action done is legal or illegal. And this has an advantage for 2 scenarios. First is for AUTISM affected people and secondly Forgery in asset documents. And if any changes in the status of the brain then it will be send to the specific person in their relation using SMS \& Email id.

\section{Introduction}

BRAIN Initiative is the ability to map the human brain at different scales with improved throughput and resolutions. A complete representation of the brain structure will provide new insights into how the human brain functions and may facilitate new treatments and drug discovery for brain disorders. Recent advances in intact brain imaging, such as the CLARITY and MAP (Magnified Analysis of the Proteome) tissue clearing techniques, make it possible to collect large volumetric images of brain tissue at cellular and sub-cellular resolutions. For efficient processing and analysis high challenge is on the high throughput and high resolution in brain imagery [1].

Brain graphs offer a framework to represent the structural or functional topology at multiple levels. A number of software tools exist for analysing topology of brain networks using graph theory. They primarily focus on studying the correlations of anatomically separated brain regions. Few are designed for high throughput dense and long-range neuron analysis at the cellular level, which is critical for understanding brain circuits and for comparing healthy and diseased brains. High throughput and low latency analysis of brain data will require high speed databases and programming interfaces amenable to large scale graph analytics $[2,3]$.

\section{Requirements}
Hardware
* EEG Sensor
* EEG Signalling unit
* Arduino Uno
* TFT Touchscreen
* IoT Module ESP8266 


\section{Software}

* Arduino Uno IDE

\section{Virtual brain module}

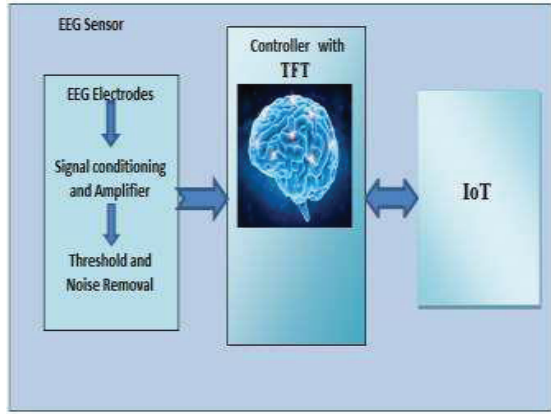

Figure 1: Structure of the project.

Description: The above figure shows the structure of the work and flow of control how it goes on.

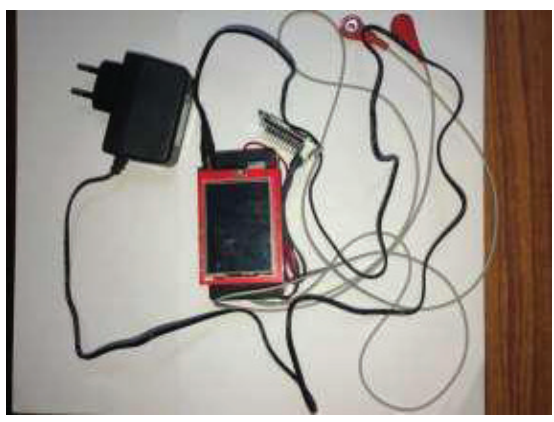

Figure 2: Device before Activation.

Description: The above figure shows the hardware kit of the project after connection and before activation.

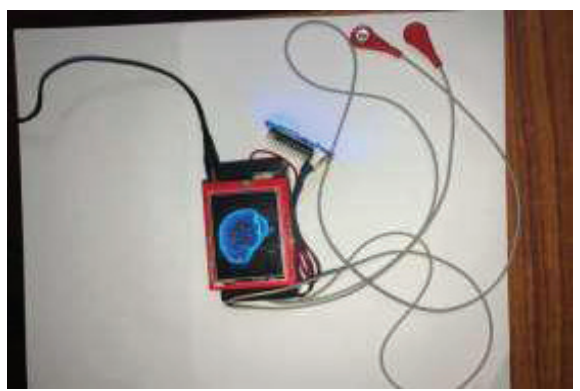

Figure 3: Device after Activation.

Description: The above figure shows the project after it gets activated and for few seconds it checks for the EEG signal.

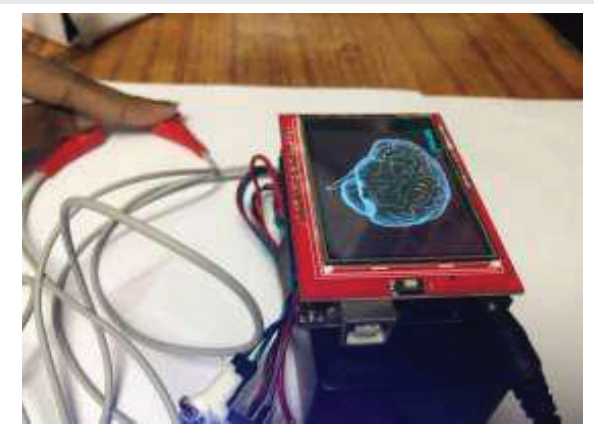

Figure 4: Device with output (NORMAL).

Description: From the above figure, it is confirmed that after the EEG signal gets received, it checks for the state of the brain whether it is normal (alive).

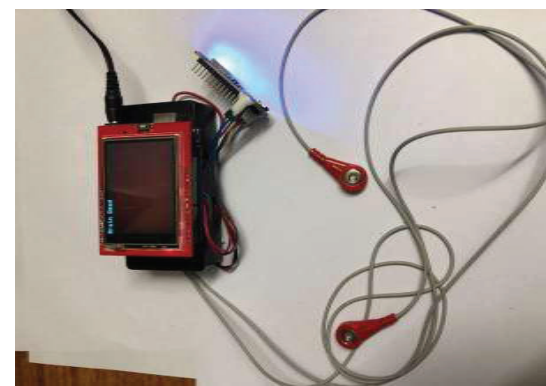

Figure 5: Device with output (ABNORMAL/ BRAIN DEAD).

Description: From the above figure, after getting the signal and checks for the

status, if it is abnormal it shows the message on the touch panel as Brain dead.

\section{Components details}

EEG sensor: EEG sensor has the work to measure the electrical activities which is generated by the synchronized activity of multiple neurons in volts which results in turn givesoutstanding resolution in terms of time, which makes us to find the activity within the limit of different divisions of cortical areas even at sub -second timescales. EEG, the fastest imaging techniques available has high sample rate. Firstly when discovered many many years ago EEG was plotted on paper. Nowadays in current systems, it digitally displays the data as a continuous flow of voltages on scenarios which we want [4-10] Figure 6.

EEG signal: EEG signal which is calculated in terms of intensity and frequency. Signal intensity is measured in microvolts $(\mu \mathrm{V})$. Signal frequency of the human. EEG waves are of four types and they are theta, delta, alpha and beta Figure 7.

Microcontroller - arduino: Arduino Microcontroller is one of the powerful single board computers that have gained special interest on the markets to make many inventions with technologies. The Arduino is open-source, means and development software is free [11].

In United States, Sparkfun is a good source in Arduino hardware. Using this Arduino board, we can create interface circuits to read switches and other sensors, and to control operations like motors and lights with less effort [12] Figure 8.

TFT touchscreen: TFT Touch Screen is an Arduino with compatible multi-coloured TFT display with compatible footprint. The TFT driver has professional Driver IC with 8 bit data and 4 bit control interface. We can draw text or do anything with the TFT library. It also has on board micro-SD card slot on the back of the screen and store bitmap images to display on the screen. The TFT library interfaces/interacts with the controller of the screen through SPI when using the TFT library Figure 9.

ESP8266: ESP8266 - Wi-Fi Module, self-contained SOC (System on Chip)/integrated circuits (i.e.), chip with connection to the TCP/IP protocol stack that can give any different microcontroller access to other Wi-Fi network. The microcontroller which we are using in this project is ARDUINO. The ESP8266 suits whether for hosting anapplication or offloading all Wi-Fi networking functions from processor of other applications. This module comes with AT commands 
firmware allows Arduino Wi-Fi shield. It's completely fast growing community support in economy. This module has on-board $80 \mathrm{MHz}$ low power 32 bit processor and supports Bluetooth co-existence interfaces; it contains special feature of self-calibrated RF which works under all operating conditions [13]. And also it has APSD - (Automatic Power Save Delivery) with power saving mechanism Figure 10.

Arduino Uno Ide: This is a cross-platform application(for Windows, macOS, Linux) that is written in the programming language Java and is used to write and upload programs to Arduino compatible boards, and also with the help of 3rd party

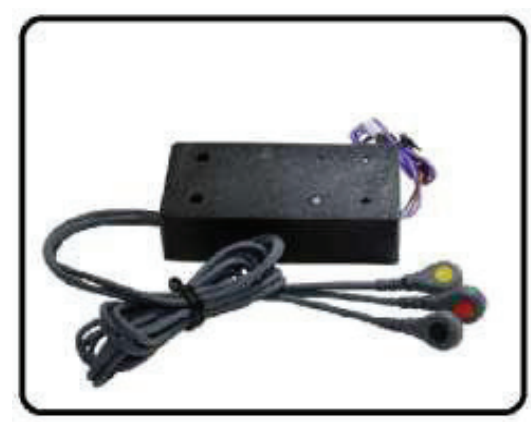

Figure 6: EEG Sensor.
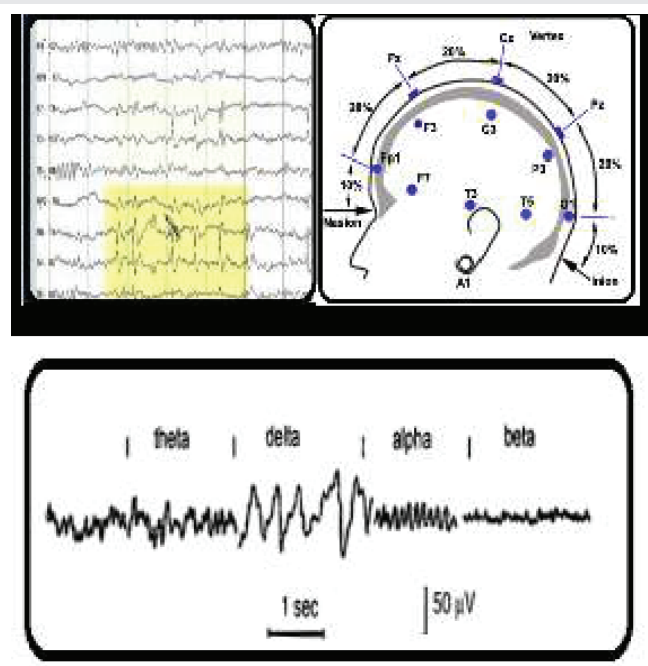

Figure 7: EEG Signal.

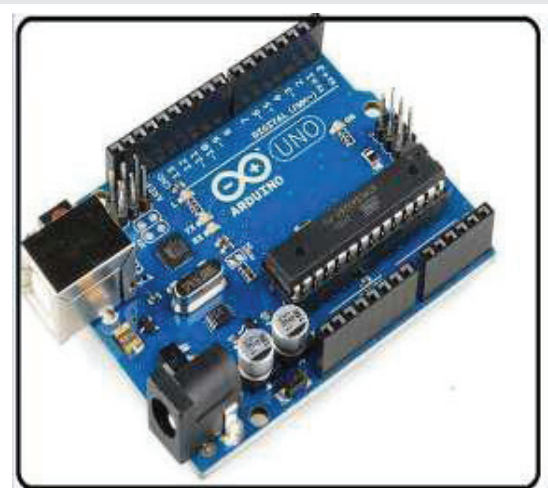

Figure 8: Arduino

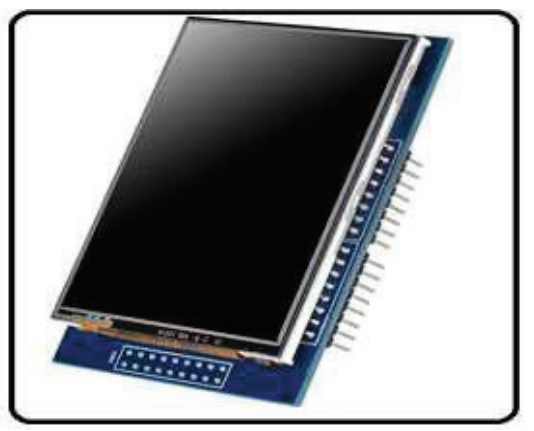

Figure 9: Touch Screen

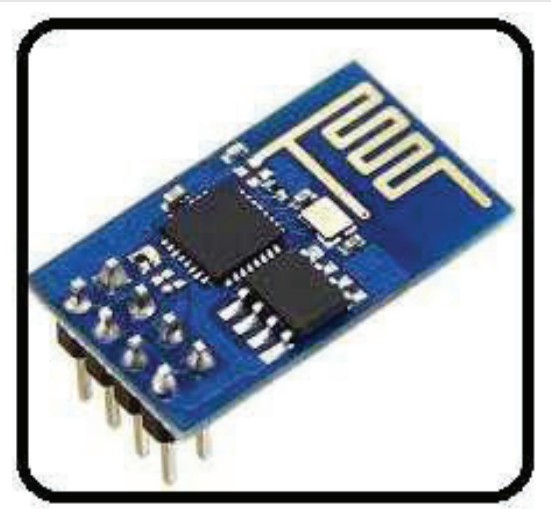

Figure 10: Wi-Fi Module.

cores, other vendor development boards. The source code for the IDE is released under the GNU General Public License, version 2. The Arduino IDE supports the languages $\mathrm{C}$ and $\mathrm{C}++$ using some special conditions with rules of code structuring [14].

\section{Implementation}

Here, firstly the EEG headset with sensor is connected to the microprocessor ARDUINO board and it is connected to the ESP8266 which is interconnected to the TFT Touchscreen. Firstly the EEG headset sensors the EEG signal from the brain with the electrodes present in the headset and it checks whether it is alive or dead. After sensing, if the result comes it is normal, and then it will be displayed on the touch screen. If we want in Software application, then we can check the status of the brain in ARDUINO IDE using the cable connected to hardware kit and the device is to be installed into the system/ laptop in which Arduino software has been installed. In Tools menu, present in the Arduino application, click on the port which is enabled and after that we can directly see the status of the brain in the monitor. If any modification or update is noticed then the status will be sent through SMS and Email id for specific person in contact [15-17] Figure 11.

\section{Conclusion \& future enhancement}

In this paper, we described a cloud-based system for performing large-scale brain connectivity analysis. We demonstrated that our approach can achieve fast data query and extraction for analytics and visualization. There are many avenues for future work. First, we would like to enhance the web 


\section{Brain Status Logs}

Click here to delete logs CLEARLOG

\begin{tabular}{|l|l|l|l|}
\hline LogID & Data & Logdate & LogTime \\
\hline 1 & Normal & $04-11-19$ & $19: 28: 44$ \\
\hline 2 & Normal & $04-11-19$ & $19: 36: 56$ \\
\hline 3 & Normal & $04-25-2019$ & $12: 44: 03$ \\
\hline 4 & Brain_Dead & $04-25-2019$ & $12: 45: 46$ \\
\hline 5 & Normal & $04-25-2019$ & $12: 51: 23$ \\
\hline 6 & Brain_Dead & $04-25-2019$ & $12: 52: 34$ \\
\hline 7 & Normal & $04-25-2019$ & $12: 55: 31$ \\
\hline 8 & Brain_Dead & $04-25-2019$ & $12: 56: 17$ \\
\hline
\end{tabular}

Figure 11: Brain Status Table with date and time.

GUI by making it more interactive and user friendly. Further, we intend to scale up to process much larger datasets (terabytes and above) with the goal of one day being able to perform such analysis on the human brain. We are also exploring the use of a polystore database such as BigDAWG as a data. Here we are using logid for every user, through that they are accessing their data. In future, thumb impression for every user can be added instead of logid. With this logid, misuse of data is possible. And this great kit can be converted into a chip and can insert either internally or externally. For autism people and illness people this can be inserted internally. And also, every person can use this in day to day life and can definitely escape from accidental health issues and also from forgeries being done without the particular person's knowledge.

\section{References}

1. Surekha M, Aswathy RH (2015) A Survey Paper-EEG Based Keyboard for Crippled with Mind Wave Sensor using IAUI. International Conference on Advanced Computing and Communication Systems.

2. Mahmud M, Hawellek D, Valjamae A (2009) A Brain Machine Interface Based on EEG: Extracted Alpha Waves Applied to Mobile Robot. 2009 Advanced Technologies for Enhanced Quality of Life. Link: https://bit.ly/2Xn19ZS

3. Raajan NR, Jayabhavani GN (2007) A smart way to play using Brain Machine Interfacing. 2013 International Conference on Information Communication and Embedded Systems (ICICES). Link: https://bit.ly/3hEZeHe

4. Chen X, Wang Y, Gao S, Jung TP, Gao X (2015) Filter bank canonical correlation analysis for implementing a high-speed SSVEP-based brain-computer interface. Journal of Neural Engineering 12. Link: https://bit.ly/3lvCc73
5. Han JH, Kim JH, Shin J, Chen Y, Chang S, et al. (2014) Non- Invasive Optical Methods for Brain Machine Interfacing and Imaging. 2014 IEEE International Conference on Systems, Man, and Cybernetics (SMC). Link: https://bit.ly/3IBOVVC

6. Francisco Á, Ricardo RA, Leandro SS, Salvador SR (2014) BCl-based Navigation in Virtual and Real Environments. 12th International Work-Conference on Artificial Neural Networks.

7. Krusienski DJ, Shih JJ (2011) Control of a Visual Keyboard Using an Electrocortico graphic Brain- Computer Interface, Neurorehabilitation and neural repair 25: 323-331. Link: https://bit.ly/3nLKQ3V

8. Chatterjee R, Bandyopadhyay T (2016) EEG based Motor Imagery Classification using SVM and MLP. 2nd International Conference on Computational Intelligence and Networks (CINE). 84-89. Link: https://bit.ly/3Cj8atW

9. EhsanKamrani SK, Hahn SH, Yun A (2015) Optical EEG (OEEG): A Nove Technique toward Plug and Play Non-Invasive Brain Imaging and Human Machine Interfacing. Link: https://bit.ly/3hJ5rlz

10. Muelle JP (2014) What is the Internet of Things?

11. Bi L, Lian J, Jie K, Lai R, Liu Y (2014) A speed and direction-based cursor control system with P300 and SSVEP. Biomedical Signal Processing and Control 14 126-133. Link: https://bit.ly/3EvbT9Q

12. Ponce P, Molina A, Balderas DC, Grammatikou D (2014) Brain compute interfaces for cerebral palsy. Cerebral Palsy-Challenges for the Future 2014. Link: https://bit.ly/3kgFxHr

13. Gandhi V, Prasad G, McGinnity TM, Coyle D, Behera L (2013) Intelligent adaptive user interfaces for $\mathrm{BCl}$ based robotic control. Proceedings of the Fifth International Brain-Computer Interface Meeting. Link: https://bit.ly/3tNIYso

14. Chambayil B, Singla R, Jha R (2010) EEG Eye Blink Classification Using Neura Network. Proceedings of the World Congress on Engineering 2-5. Link: https://bit.ly/2XBrQun

15. Chambayil B, Singla R, Jha R (2010) Virtual Keyboard BCl using Eye blinks in EEG. IEEE $6^{\text {th }}$ International Conference on Wireless and Mobile Computing Networking and Communications. Link: https://bit.ly/3zjMGvd

16. Huang H, Hu L, Xiao F, Du A, Ye N, et al. (2019) An EEG-Based Identity Authentication System with Audiovisual Paradigm in IoT. Sensors 19: 1664 Link: https://bit.ly/2XqGm7A

17. Khaled H, Abu-Elnasr O, Elmougy S, Tolba AS (2021) Intelligent System for human activity recognition in loT environment. Complex \& Intelligent Systems. Link: https://bit.ly/2XzucKb

\section{Discover a bigger Impact and Visibility of your article publication with}

Peertechz Publications

\section{Highlights}

* Signatory publisher of ORCID

* Signatory Publisher of DORA (San Francisco Declaration on Research Assessment)

* Articles archived in worlds' renowned service providers such as Portico, CNKI, AGRIS, TDNet, Base (Bielefeld University Library), CrossRef, Scilit, J-Gate etc.

* Journals indexed in ICMJE, SHERPA/ROMEO, Google Scholar etc.

* OAI-PMH (Open Archives Initiative Protocol for Metadata Harvesting)

* Dedicated Editorial Board for every journa

* Accurate and rapid peer-review process

* Increased citations of published articles through promotions

- Reduced timeline for article publication

Submit your articles and experience a new surge in publication services (https://www.peertechz.com/submission).

Peertechz journals wishes everlasting success in your every endeavours. 